\title{
Condutância da folha em milho cultivado em plantio direito e convencional em diferentes disponibilidades hídricas
}

\author{
Leaf conductance of maize cropped in no tillage and conventional tillage in different water availability
}

\author{
Cleusa Adriane Menegassi Bianchi ${ }^{1}$ João Ito Bergonci ${ }^{\text {II }}$ Homero Bergamaschi ${ }^{\text {III }}$ \\ Genei Antonio Dalmago ${ }^{\text {VV }}$ Bruna Maria Machado Heckler ${ }^{\text {V Flávia Comiranv }}$
}

\section{RESUMO}

A ocorrência de déficit hídrico durante o desenvolvimento da cultura do milho pode causar alterações nos processos fisiológicos da cultura. O objetivo deste trabalho foi avaliar alterações na condutância foliar da cultura do milho, cultivado em dois sistemas de manejo do solo, com diferentes disponibilidades hídricas. $O$ milho foi cultivado em plantio direto (PD) e convencional (PC) com irrigação (I2) de forma a manter a umidade do solo próxima à capacidade de campo, irrigação parcial (I1) correspondente a $41 \%$ da água aplicada em I2, e sem irrigação (I0). As medições de condutância foliar foram realizadas às 10 e 13 horas (hora local), sendo denominadas de condutância foliar máxima $e$ mínima, respectivamente. Durante o crescimento vegetativo, os menores valores de condutância máxima e mínima ocorreram em plantio direto. Contudo, quando o índice de área foliar máximo foi alcançado, a partir do pendoamento, as plantas de milho em plantio direto apresentaram maior condutância, indicando maior disponibilidade de água no solo, neste sistema.

Palavras-chave: Zea mays, plantio direto, déficit hídrico, potencial da água na folha.

\section{ABSTRACT}

The occurrence of water deficit during the maize crop cycle may affect the physiological processes of plants. The objective of this research was to evaluate alterations in the leaf conductance of maize plants, submitted to different soil tillage systems and water availability in the soil. A field experiment was carried out in the Estação Experimental Agronômica of the Universidade Federal do Rio Grande do Sul, in the summer season of 2002/03. The maize was cropped in no-tillage (NT) and conventional tillage (CT) systems, with full irrigation (I2) necessary to maintain the soil moisture close to the field capacity, partial irrigation (I1) corresponding to $41 \%$ of the water application in I2, and non-irrigation (I0). The measurements were taken at $10 \mathrm{~h}$ and $13 \mathrm{~h}$ (local time), in order to characterize the maximum and minimum leaf conductance, respectively. During the vegetative plant growing, the lowest values of either maximum and minimum leaf conductance occurred in the notillage system. However, since the maximum leaf area index was achieved (at tasseling stage), the maize plants cropped in no-tilt soil presented the highest leaf conductance, indicating a higher soil water availability in NT than in CT.

Key words: Zea mays, no-tillage, water deficit, leaf water potential.

\section{INTRODUÇÃO}

Na agricultura, a ocorrência de déficit hídrico no solo é o fator mais importante na determinação do rendimento das espécies. O milho tem seu rendimento diminuído na presença do déficit hídrico, principalmente se este ocorrer no período crítico da cultura (BERGONCI et al., 2001).

A atividade agrícola teve importantes modificações em relação ao manejo do solo nas últimas décadas, entre as quais o plantio direto. Este sistema promove alterações nas propriedades físicas

IDepartamento de Plantas Forrageiras e Agrometeorologia, Universidade Federal do Rio Grande do Sul (UFRGS), CP 15.100, 91501-970, Porto Alegre, RS, Brasil. E-mail: cleusa_bianchi@yahoo.com.br. Autor para correspondência.

IDepartamento de Botânica, UFRGS. Porto Alegre, RS, Brasil. E-mail: joao.bergonci@ufrgs.br.

IIIDepartamento de Plantas Forrageiras e Agrometeorologia, Universidade Federal do Rio Grande do Sul, Porto Alegre, RS, Brasil.

E-mail: homerob@ufrgs.br.

IvUniversidade Estadual do Rio Grande do Sul (UERGS). Porto Alegre, RS, Brasil. E-mail: gdalmago@yahoo.com.br.

${ }^{v}$ Curso de Agronomia, UFRGS, Porto Alegre, RS, Brasil. 
(DERPSCH, et al., 1986), químicas (SIDIRAS et al., 1983) e biológicas do solo (GRIFFITH et al., 1992), em relação ao sistema de plantio convencional. Portanto, sabe-se que se trata de tecnologia importante para minimizar os efeitos do déficit hídrico, pelo fato de disponibilizar mais água às plantas (DALMAGO et al., 2004).

O déficit hídrico pode levar as células a perder sua turgidez, dependendo da sua intensidade. Provoca, assim, alterações nos processos de expansão celular, na fotossíntese e nas trocas gasosas com o ambiente(KRAMER \& BOYER, 1995). O déficithídrico afeta praticamente todos os aspectos relacionados ao crescimento das culturas: reduz a área foliar (por diminuir o crescimento ou pela senescência acelerada de folhas), diminui a fotossíntese (pela diminuição da área foliar, murchamento e enrolamento de folhas e fechamento de estômatos) e afeta outros processos, como brotação, polinização, absorção de nutrientes e translocação de fotossintatos (BERGAMASCHI, 1992).

O uso de indicadores da condição hídrica das plantas, como a condutância foliar, pode ser importante no monitoramento da disponibilidade de água no solo e da necessidade de irrigação. Outros indicadores da condição hídrica das plantas, como o potencial mínimo da água na folha e o potencial osmótico, também evidenciam alterações sob déficit hídrico (PREMACHANDRA et al., 1992).

A condutância foliar pode ser considerada como uma medida da permeabilidade da folha à difusão de água e $\mathrm{CO}_{2}$, sendo o fluxo difusivo proporcional à força impulsora e inversamente proporcional à resistência (SALISBURY \& ROSS, 1994). O controle estomático da condutância foliar ao vapor de água é um importante mecanismo através do qual o vegetal limita a sua perda.

O fechamento estomático pode ocorrer dentro de uma larga faixa de potencial da água na folha, dependendo da espécie (JONES, 1985). Para o milho, os estômatos se fecham com potenciais da água na folha entre -1,7 e -2,0 MPa (BERGONCI \& PEREIRA, 2002). BONO et al. (2001) e BERGONCI et al. (2000) verificaram diminuição na condutância estomática do milho quando o potencial da água na folha chegou a 1,5 MPa.

A hipótese deste trabalho foi a de que, durante períodos de estiagens, a condutância foliar se mantém mais elevada no sistema de plantio direto pelo fato de o solo armazenar maior quantidade de água. $\mathrm{O}$ objetivo deste trabalho foi avaliar padrões de variação na condutância foliar em milho irrigado e não-irrigado, cultivado em plantio direto e convencional.

\section{MATERIAL E MÉTODOS}

O experimento foi conduzido na Estação Experimental Agronômica da Universidade Federal do Rio Grande do Sul (EEA/UFRGS), localizada em Eldorado do Sul, RS ( $30^{\circ} 05^{\prime}$ S, $51^{\circ} 40^{\prime}$ W e altitude de $40 \mathrm{~m}$ ). O clima da região é do tipo fundamental Cfa, pela classificação climática de Köeppen, ou seja, subtropical úmido com verão quente (BERGAMASCHI et al., 2003). O solo é classificado como Argissolo Vermelho Distrófico típico, segundo EMBRAPA (1999).

A área experimental, de aproximadamente 0,5ha, foi cultivada por sete anos, sendo metade dela sob plantio direto (PD) e em parte sob plantio convencional (PC). O preparo do solo foi feito em outubro de 2002, quando a área em PD teve a cobertura vegetal dessecada e acamada com o auxílio de um rolofaca. No mesmo período, na área de PC, fez-se a incorporação da biomassa verde de aveia+ervilhaca através de uma aração com arado de disco, seguida de duas gradagens com grade niveladora. A semeadura foi efetuada no dia 25 de novembro de 2002 e a emergência das plantas (50\%) ocorreu no dia 02 de dezembro de 2002.

Utilizou-se um delineamento em faixas com quatro repetições, a partir de um sistema de aspersão em linha localizado na faixa central da área (HANKS et al., 1980). Os tratamentos consistiram de dois sistemas de manejo (PD e PC) e três níveis de água. Os dois sistemas de manejo constituíram as parcelas principais e os níveis de água as subparcelas. Os níveis de água aplicados foram: I2 com dose de rega necessária para elevar a umidade do solo à capacidade de campo, I1 com dose de rega correspondente a $41 \%$ da dose necessária para atingir a capacidade de campo e I0 sem irrigação. A irrigação era efetuada quando um tensiômetro, instalado a $45 \mathrm{~cm}$ de profundidade no tratamento I2, registrava potencial da água no solo de -0,03MPa. Utilizou-se um sistema de irrigação por aspersão em linha, constituído por 12 aspersores dispostos na direção leste-oeste, na faixa central do experimento, entre os dois sistemas de manejo e com espaçamento de $6 \mathrm{~m}$ entre eles.

A adubação de base foi feita na linha de semeadura, sendo aplicados $800 \mathrm{~kg} \mathrm{ha}^{-1}$ da formulação N-P $\mathrm{P}_{2}-\mathrm{K}_{2} \mathrm{O}$ 5-20-20 na forma de uréia, superfosfato triplo e cloreto de potássio. Posteriormente, foram aplicados $120 \mathrm{~kg} \mathrm{ha}^{-1}$ de N, em cobertura na forma de uréia, em duas doses de $60 \mathrm{~kg} \mathrm{ha}^{-1} \mathrm{de} \mathrm{N}$, aos 15 e 36 dias após a emergência (DAE).

O potencial matricial da água no solo foi medido por tensiômetros de coluna de mercúrio, instalados a 45 e $60 \mathrm{~cm}$ de profundidade. Mediu-se o 
potencial da água na folha com uma câmara de pressão (modelo 3000, Soil Moisture Co., EUA), conforme BOYER (1967). As medições foram feitas às 13h em folhas totalmente expandidas e expostas ao sol, em três repetições.

A condutância foliar foi medida com um porômetro de estado estacionário da marca LICOR (modelo 1600M). Mediu-se a condutância foliar em ambas as faces foliares com três repetições, sendo a condutância total obtida pelo somatório das condutâncias das faces abaxial e adaxial, considerando que estas se encontram em paralelo. Utilizou-se folhas ensolaradas e totalmente expandidas. As medições foram feitas às $10 \mathrm{~h}$ e $13 \mathrm{~h}$ (hora local), em razão dos resultados obtidos por BERGONCI et al. (2000), que observaram valores máximos de condutância foliar às $10 \mathrm{~h}$ e mínimos às $13 \mathrm{~h}$. Os dias de medição da condutância foliar foram: 15, 17 e 29 de janeiro e 04, 18 e 28 de fevereiro de 2003, correspondendo aos 44, 46, $58,64,78$ e 88 DAE.

Os dados obtidos foram submetidos a análise de variância e as médias foram comparadas pelo teste de Tukey (t), adotando-se como critério de significância valores de $\mathrm{P} \leq 0,05$.

\section{RESULTADOS E DISCUSSÃO}

No período inicial de crescimento da cultura (dezembro), ocorreram precipitações pluviais acima da média climatológica (Figura 1). No final de dezembro e início de janeiro, houve uma curta estiagem. Entretanto, como as plantas estavam no início do crescimento, a demanda por água ainda era baixa, em razão do reduzido índice de área foliar, não acarretando déficit hídrico severo para a cultura em razão da sua baixa evapotranspiração.

A partir de 54 DAE (25 de janeiro), observouse uma situação de déficit hídrico mais intenso, caracterizada pela ausência de precipitação e densidade de radiação solar global elevada $\left(27,6 \mathrm{MJ} \mathrm{m}^{-2} \mathrm{~d}^{-1}\right)$, determinando um aumento na ETo. Nesse período, a cultura do milho se encontrava com elevado índice de área foliar e em pleno período crítico (pendoamentoespigamento \pm 55 DAE), razão pela qual observou-se o efeito do déficit hídrico no rendimento final de grãos (BERGAMASCHI et al., 2004). A partir do início de fevereiro, ocorreram precipitações que totalizaram 196mm, valor bem acima da média histórica de 110,9mm, possibilitando a recuperação hídrica da cultura.

A condutância foliar máxima $\left(g_{\text {máx }}\right)$ está representada na figura 2 , onde se observa que os maiores valores de $g_{\text {máx }}$ ocorreram nas parcelas irrigadas e os menores naquelas não irrigadas, independentemente do sistema de manejo, embora as diferenças não tenham sido estatisticamente significativas.

Apesar disso, e do fato de não ter havido interação entre os fatores, optou-se por fazer a descrição dos resultados comparando os sistemas de manejo nos dois níveis de irrigação levando-se em consideração o desvio padrão das médias. Com isso, buscou-se avaliar a tendência da evolução temporal

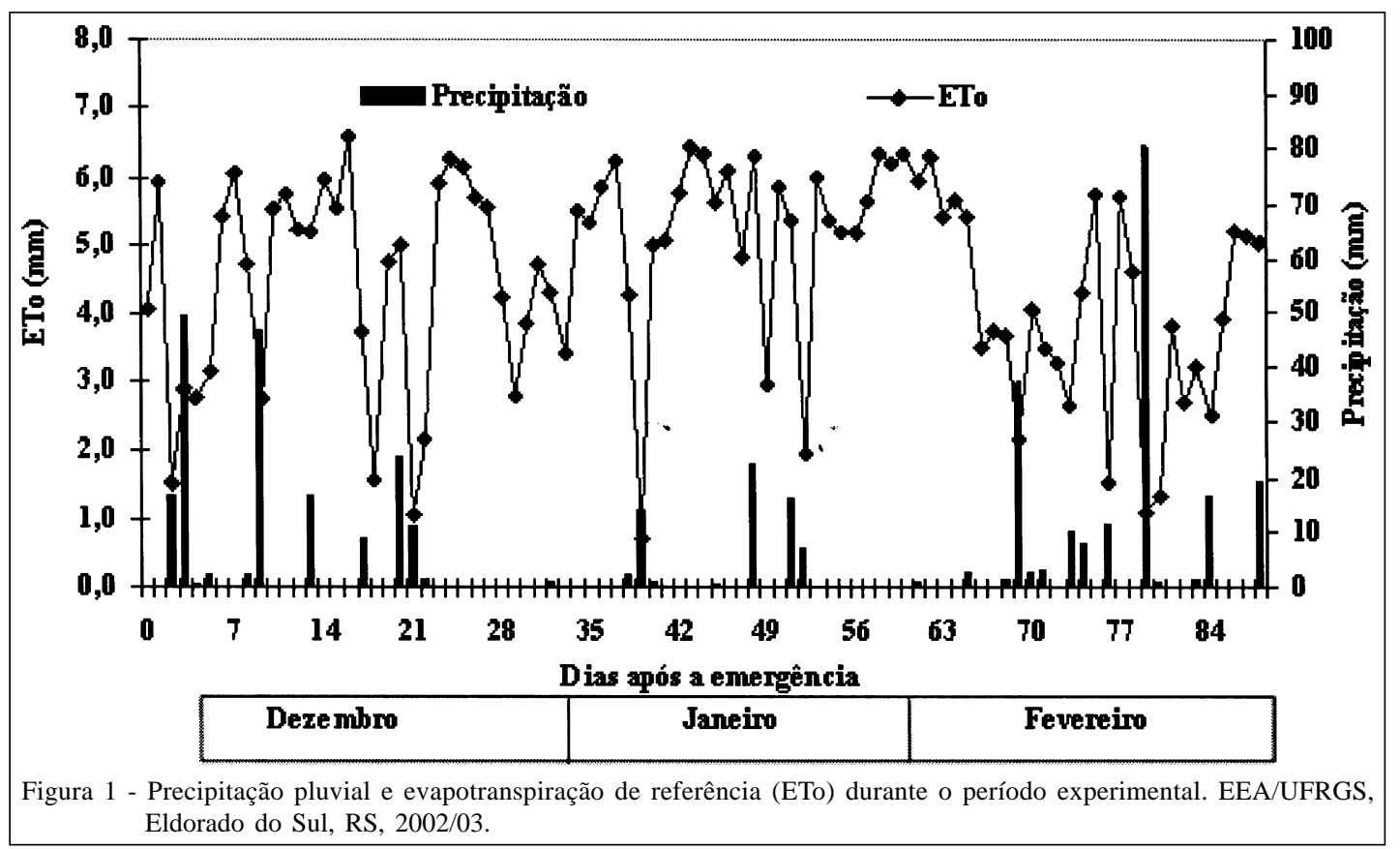

Ciência Rural, v.37, n.2, mar-abr, 2007. 


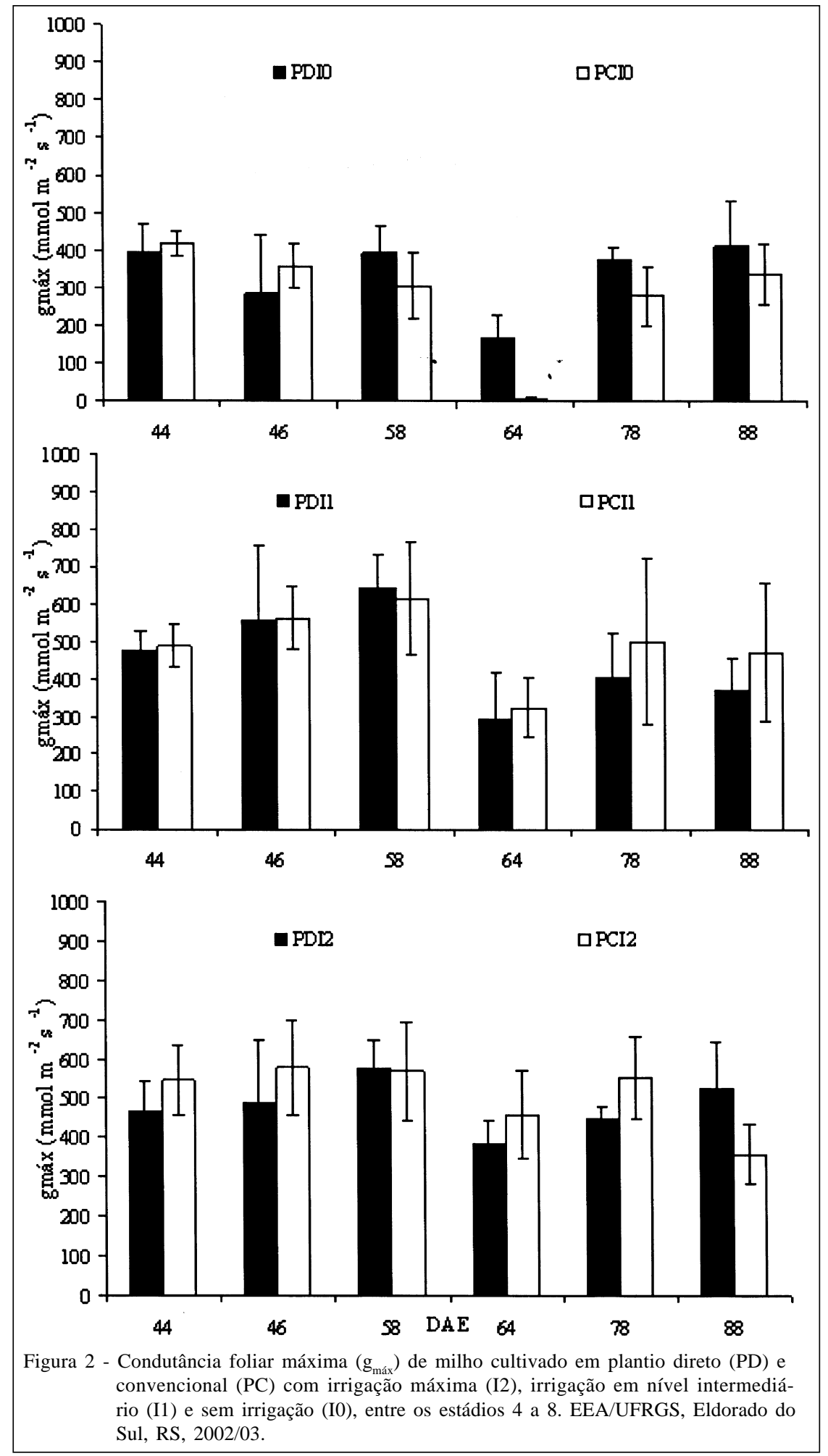

dos processos fisiológicos em plantio direto, que é uma das principais características que o difere do plantio convencional, em que o processo evolutivo é mais lento e interrompido a cada preparo (DALMAGO et al 2004).
Analisando-se as parcelas sem irrigação, pode-se observar que, aos 44 e $46 \mathrm{DAE}, \mathrm{g}_{\operatorname{máx}}$ foi maior em PC do que em PD (Figura 2). Isso pode estar associado a um maior aprofundamento do sistema 
radicular em PC, na primeira metade do ciclo, conforme observado por DALMAGO et al. (2004), o que possibilitaria maior absorção de água.

A partir dos $58 \mathrm{DAE}, \mathrm{g}_{\text {máx }}$ foi maior em $\mathrm{PD}$, indicando maior disponibilidade de água neste sistema. Observa-se, também, uma diminuição de gáx $_{\text {a }} 64 \mathrm{DAE}$, em razão do aumento da demanda evaporativa atmosférica (Figura 1), sendo $g_{\text {máx }}$ maior em PD. Da mesma forma, YONG et al. (1997) observaram queda linear da condutância estomática frente ao déficit de pressão de vapor entre a folha e o ar. Por outro lado, EAMUS \& SHANAHAN (2005) mostraram que a resposta da condutância ao déficit de pressão de vapor depende do estado hídrico das folhas, sendo a condutância mais sensível a baixos potenciais da água.

A 64 DAE, g $g_{\text {máx }}$ diminuiu em ambos os sistemas de manejo nas parcelas sem irrigação (Figura 2), sendo de $6 \mathrm{mmol} \mathrm{m}^{-2} \mathrm{~s}^{-1} \mathrm{em}$ PC e $165 \mathrm{mmol} \mathrm{m}^{-2} \mathrm{~s}^{-1} \mathrm{em}$ $\mathrm{PD}$. Isso indica que a redução da abertura dos estômatos foi mais acentuada em PC do que em PD, demonstrando melhor condição hídrica das plantas cultivadas sob PD.

Após o 64 DAE, $g_{\text {máx }}$ aumentou em I0 em ambos os sistemas de manejo (figura 2). Contudo, as plantas cultivadas sob PD apresentaram maior $g_{\text {máx }}$, demonstrando uma melhor condição hídrica, pois essas plantas estiveram por mais tempo com os estômatos abertos, reduzindo a limitação estomática e possibilitando trocas gasosas com o ambiente, o que mantém a atividade fotossintética.

A redução da abertura estomática pode estar relacionada à menor disponibilidade de água no solo, que causa maior resistência no transporte de água, tanto do solo quanto das raízes (TARDIEU et al., 1993). A redução do fluxo de água no sistema solo-plantaatmosfera, devido aos baixos potenciais da água no solo, reduz a condutividade hidráulica dos tecidos condutores que, por sua vez, diminuem os fluxos de água para as folhas, com conseqüente queda na turgidez das células estomáticas, causando fechamento dos estômatos (SPERRY, 2000). Essa é uma resposta direta, também em função da diferença entre níveis de vapor d’água entre a folha e o ar, que eleva a transpiração e desencadeia o fechamento estomático (SCHULZE, 1986).

Nas parcelas com irrigação próxima à capacidade de campo (Figura 2), $g_{\text {máx }}$ foi menor em PD em quatro dos seis dias avaliados. Quando $g_{\text {máx }}$ é alta, a transpiração das plantas é maior, resultado da melhor condição hídrica do solo e da planta, que propicia a continuação do fluxo de água ao longo do sistema soloplanta-atmosfera. Conforme trabalho realizado durante a condução deste experimento, em parcelas irrigadas próximo à capacidade de campo, em dois anos, percebeu-se maiores taxas de transpiração em PC no período inicial do crescimento das plantas. Entretanto, esta passou a ser maior em PD no período do pendoamento-espigamento (DALMAGO et al., 2003). Isso vem ao encontro dos maiores valores de $g_{\text {máx }}$ em PC, observados no período inicial do crescimento do milho, até $46 \mathrm{DAE}$, e no pendoamento-espigamento, quando $g_{\text {máx }}$ foi maior em PD (58 e $88 \mathrm{DAE}$ ). Conforme DALMAGO et al. (2003), os maiores valores de transpiração em PC, no período inicial do crescimento das plantas, ocorreram devido à maior capacidade de exploração do solo pelas raízes dessas plantas, uma vez que os nutrientes se encontram em camadas mais profundas do solo. Durante o pendoamentoespigamento, a transpiração foi maior em PD, apesar da ocorrência de um pequeno déficit hídrico. Sob PD, observou-se, então, uma melhor condição hídrica das plantas, proporcionada por uma maior disponibilidade de água no solo, principalmente na camada mais superficial, devido à maior quantidade de matéria orgânica (DALMAGO et al., 2003).

Observa-se, também, que, durante cinco dos seis dias de medições, $g_{\text {máx }}$ apresentou a mesma tendência em relação aos sistemas de manejo, ou seja, inicialmente maior em PC e após maior em PD. Já aos 64 e 78 DAE, observou-se que g $_{\text {máx }}$ tendeu a ser maior em PD nas parcelas sem irrigação e menor nas parcelas com irrigação próxima à capacidade de campo.

Na figura 3, está representada a condutância foliar mínima ( $\mathrm{g}_{\text {min }}$ ) observada em todos os tratamentos. A 44 e 46 DAE $_{\text {mín }}$ foi maior em PC e, após este período, até $088 \mathrm{DAE}, \mathrm{g}_{\min }$ foi sempre maior em $\mathrm{PD}$, seguindo a mesma tendência dos valores de $g_{\text {máx }}$, ou seja, maior em PC no início e, após, em PD. Somente a amplitude dos valores foi menor, pois as medições foram feitas nas horas de maior demanda evaporativa. Nas parcelas com irrigação próxima à capacidade de campo, $\mathrm{g}_{\text {mín }}$ mostrou-se menor em PD, em cinco dos seis dias analisados.

O fato da $\mathrm{g}_{\operatorname{mín}}$ e da $\mathrm{g}_{\max }$ terem sido menores em $\mathrm{PD}$, na maioria dos dias, reflete que, em uma situação de elevada demanda evaporativa, as plantas sob PD apresentaram características conservadoras de água. Houve uma diminuição da condutância foliar, de forma a manter a turgidez das folhas, mesmo estando essas plantas com potencial mínimo da água na folha elevado (dados não mostrados) em relação às plantas sob PC, durante esses dias, sem cessar o fluxo transpiratório. Essa tendência foi observada por TURNER (1974), ao estudar a condutância de milho em plantas irrigadas e não-irrigadas, sendo que as plantas irrigadas apresentaram diminuição da condutância foliar, quando 


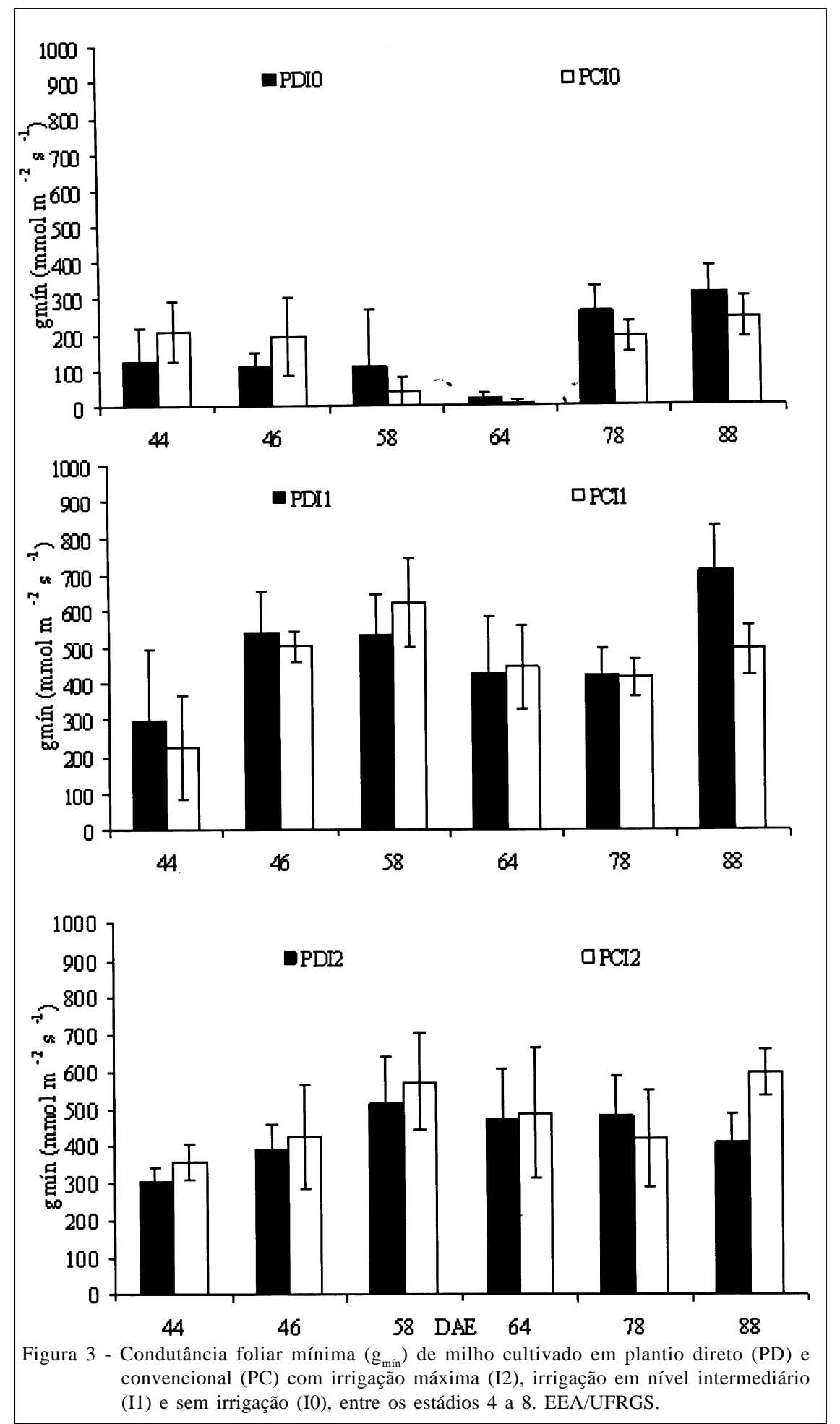

comparada com as não-irrigadas. TORRECILLAS et al. (1995), estudando as relações hídricas em duas variedades de tomate submetidas a déficit hídrico, também observaram menor condutância em uma das variedades estudadas, mesmo após a reidratação. Os autores consideraram que esta variedade apresentou um mecanismo de proteção ao déficit, pois manteve sua condutância baixa, a fim de recuperar sua turgidez mais rapidamente. Isso também vem ao encontro da ocorrência de menor ajuste osmótico observado nas 
plantas sob PD, quando comparadas àquelas em PC. Como estas estiveram com maior suprimento hídrico, o grau de ocorrência de ajuste osmótico não foi muito elevado, quando comparado ao sistema PC (BIANCHI et al., 2005).

Quando se compara g $_{\text {mín }}$ entre os níveis de irrigação, observa-se a mesma tendência de $g_{\text {máx }}$ nos três primeiros dias de medições. De 58 a 88 DAE, na ausência de irrigação, $g_{\text {mín }}$ foi maior em PD, enquanto que, nas plantas irrigadas, $g_{\text {máx }}$ foi maior em PD apenas a $78 \mathrm{DAE}$. Estes resultados parecem indicar a ocorrência de uma maior disponibilidade hídrica em PD, conforme foi observado por DALMAGO et al. (2004).

\section{CONCLUSÃO}

A condutância foliar é maior no período inicial de crescimento em milho cultivado em solo sob preparo convencional e, a partir do pendoamento, ela é maior sob plantio direto. A condutância foliar do milho tem relação direta com o nível de disponibilidade de água no solo, independentemente do sistema de manejo do solo.

\section{AGRADECIMENTOS}

À Coordenação de Aperfeiçoamento de Pessoal de Nível Superior (CAPES), pela bolsa de mestrado concedida à primeira autora. Ao Conselho Naional de Desnvolvimento Científico e Tecnológico (CNPq), pelas demais bolsas concedidas.

\section{REFERÊNCIAS}

BERGAMASCHI, H. Desenvolvimento de déficit hídrico em culturas. In: BERGAMASCHI, H. (Coord). Agrometeorologia aplicada à irrigação. Porto Alegre: UFRGS, 1992. p.25-32.

BERGAMASCHI, H. et al. Clima da Estação Experimental da UFRGS (e região de abrangência). Porto Alegre: UFRGS, 2003. 77p.

BERGAMASCHI H. et al. Distribuição hídrica no período crítico do milho e produção de grãos. Pesquisa Agropecuária Brasileira, v.39, p.831-839, 2004.

BERGONCI, J.I et al. Condutância foliar como um indicador de déficit hídrico em milho. Revista Brasileira de Agrometeorologia, v.8, n.1, p.27-34, 2000.

BERGONCI, J.I. et al. Eficiência da irrigação em rendimento de grãos e matéria seca de milho. Pesquisa Agropecuária Brasileira, v.36, n.7, p.949-956, 2001

BERGONCI, J.I.; PEREIRA, G.B. Comportamento do potencial da água na folha e da condutância estomática do milho em função da fração de água disponível no solo. Revista Brasileira de Agrometeorologia, v.10, n.2, p.229-235, 2002.
BIANCHI, et al. Ajuste osmótico em milho cultivado em diferentes sistemas de manejo de solo e disponibilidade hídrica. Pesquisa Agropecuária Brasileira, v.40, n.7, p.645-651, 2005.

BONO, L. et al. Alterações no padrão de resposta à luz da condutância estomática do milho causado pelo déficit hídrico. Revista Brasileira de Agrometeorologia, v.9, n.1, p.2734, 2001.

BOYER, J.S. Leaf water potential measured with a pressure chamber. Plant Physiology, v.43, n.1, p.1053-1062, 1967.

DALMAGO, G.A. et al. Transpiração do milho cultivado em sistema de plantio direto e convencional. In: CONGRESSO BRASILEIRO DE AGROMETEOROLOGIA, 13., 2003, Santa Maria. Anais... Santa Maria: UNIFRA SBA UFSM, 2003. V.1, p.297-298.

DALMAGO, G.A. et al. Evapotranspiration in maize crops as function of soil tillage systems. In: INTERNATIONAL SOIL CONSERVATION ORGANISATION CONFERENCE, 13., 2004, Brisbane. Conference Proceedings... Brisbane: Australian Society of Soil Science Incorported and International Erosion Control Association, 2004. p.1-4 (Paper n. 780).

DERPSCH, R. et al. Results of studies made from 1977 to 1984 to control erosion by cover and no-tillage techniques in Parana, Brasil. Soil \& Tillage Research, v.8, p.253-263, 1986.

EAMUS, D.; SHANAHAN, S.T. A rate equation model of stomatal responses to vapour pressure deficit and drought. BMC Ecology, v.2, n.8. Acessado em 20 jun. 2005. On line. Disponível em: www.biomedcentral.com/1472-6785/ $2 / 8$.

EMBRAPA. Sistema Brasileiro de Classificação de Solos. Rio de Janeiro: Centro Nacional de Pesquisa de Solos, 1999. 412p.

GRIFFITH, D.R. et al. Crop response to tillage systems. In: Conservation tillage systems and management: crop residue management with no-till, ridge-till, mulchtill. Ames: Midwest Plat Service, 1992. p.25-33.

HANKS, R.J. et al. Statistical analysis of results from irrigation experiments using the line-source sprinkler system. Soil Science Society of America Journal, v.44, p.886-888, 1980.

JONES, C.A. C4 grasses and cereals: growth, development and stress response. New York: John Wiley \& Sons, 1985. 419p.

KRAMER, P.J.; BOYER J.S. Water relations of plants and soils. San Diego: Academic, 1995. 495p.

PREMACHANDRA, G.S. et al. Osmotic adjustment and stomatal response to water deficits in maize. Journal of Experimental Botany, v.43, p.1451-1456, 1992.

SALISBURY, F.B.; ROSS, C.W. Fisiologia vegetal. México: Iberoamerica, $1994.758 p$.

SIDIRAS, N. et al. A. Influência de diferentes sistemas de preparo do solo na variação da umidade e rendimento da soja, 
em latossolo roxo distrófico (oxisol). Revista Brasileira de Ciência do Solo, v.7, p.103-106, 1983.

SCHULZE, E.D. Whole-plant responses to drought. Australian Journal of Plant Physiology, v.13, p.127-141, 1986.

SPERRY, J.S. Hydraulic constraints on plant gas exchange. Agricultural and Forest Meteorology, v.104, n.1 p.13-23, 2000 .

TARDIEU, F. et al. Stomatal control by both [ABA] in the xylem sap and leaf water status: a test of a model for droughted or ABA-fed field-grown maize. Plant, Cell and Environment, v.16, p.413-420, 1993.

TORRECILLAS, A. et al. Water relations of two tomato species under water stress and recovery. Plant Science, v.105, p.169176, 1995.

TURNER, C.N. Stomatal behavior and water status of maize, sorghum, and tabacco under field conditions. Plant Physiology, v.53, p.360-365, 1974.

YONG, J.W.H. et al. Stomatal responses to changes in vapour pressure difference between leaf and air. Plant, Cell and Environment, v.20, p.1213-1216, 1997. 